\title{
Cost Effectiveness of Support for People Starting a New Medication for a Long-Term Condition Through Community Pharmacies: An Economic Evaluation of the New Medicine Service (NMS) Compared with Normal Practice
}

\author{
Rachel A. Elliott ${ }^{1}$ (1) Lukasz Tanajewski $^{2} \cdot$ Georgios Gkountouras $^{2} \cdot$ \\ Anthony J. Avery ${ }^{3} \cdot$ Nick Barber $^{4} \cdot$ Rajnikant Mehta $^{5} \cdot$ Matthew J. Boyd ${ }^{2} \cdot$ \\ Asam Latif ${ }^{6} \cdot$ Antony Chuter $^{7} \cdot$ Justin Waring $^{8}$
}

Published online: 3 August 2017

(C) The Author(s) 2017. This article is an open access publication

\begin{abstract}
Background The English community pharmacy New Medicine Service (NMS) significantly increases patient adherence to medicines, compared with normal practice. We examined the cost effectiveness of NMS compared with normal practice by combining adherence improvement and intervention costs with the effect of increased adherence on patient outcomes and healthcare costs.

Methods We developed Markov models for diseases targeted by the NMS (hypertension, type 2 diabetes mellitus, chronic obstructive pulmonary disease, asthma and antiplatelet regimens) to assess the impact of patients' nonadherence. Clinical event probability, treatment pathway, resource use and costs were extracted from literature and costing tariffs. Incremental costs and outcomes associated
\end{abstract}

Electronic supplementary material The online version of this article (doi:10.1007/s40273-017-0554-9) contains supplementary material, which is available to authorized users.

Rachel A. Elliott

Rachel.a.elliott@manchester.ac.uk

1 Manchester Centre for Health Economics, Room 4.318, 4th floor, Jean Mcfarlane Building, Division of Population Health, Health Services Research and Primary Care, School of Health Sciences, Faculty of Biology, Medicine and Health, The University of Manchester, Oxford Road, Manchester M13 9PL, UK

2 Division of Pharmacy Practice and Policy, The School of Pharmacy, University of Nottingham, University Park, Nottingham NG7 2RD, UK

3 Primary Care Research, Division of Primary Care, School of Medicine, Queen's Medical Centre, University of Nottingham, Nottingham NG7 2UH, UK

4 Emeritus Professor of Pharmacy, UCL School of Pharmacy, 29-39 Brunswick Square, London WC1N 1AX, UK with each disease were incorporated additively into a composite probabilistic model and combined with adherence rates and intervention costs from the trial. Costs per extra quality-adjusted life-year (QALY) were calculated from the perspective of NHS England, using a lifetime horizon.

Results NMS generated a mean of $0.05 \quad(95 \%$ CI 0.00-0.13) more QALYs per patient, at a mean reduced cost of $-£ 144$ (95\% CI -769 to 73 ). The NMS dominates normal practice with a probability of 0.78 [incremental cost-effectiveness ratio (ICER) $-£ 3166$ per QALY]. NMS has a $96.7 \%$ probability of cost effectiveness compared with normal practice at a willingness to pay of $£ 20,000$ per QALY. Sensitivity analysis demonstrated that targeting each disease with NMS has a probability over 0.90 of cost effectiveness compared with normal practice at a willingness to pay of $£ 20,000$ per QALY.

5 Research Design Service, East Midlands (RDS EM), School of Medicine, Queen's Medical Centre, University of Nottingham, Nottingham NG7 2UH, UK

6 School of Health Sciences, Faculty of Medicine and Health Sciences, Queen's Medical Centre, University of Nottingham, Nottingham NG7 2UH, UK

7 Patient and Public Representative, 68 Brighton Cottages, Copyhold Lane, Lindfield, Haywards Heath RH16 1XT, UK

8 Organisational Sociology and Improvement Science, Centre for Health Innovation, Leadership and Learning, Nottingham University Business School, Jubilee Campus, University of Nottingham, Nottingham NG8 2BB, UK 
Conclusions Our study suggests that the NMS increased patient medicine adherence compared with normal practice, which translated into increased health gain at reduced overall cost.

Trial Registration ClinicalTrials.gov Trial reference number NCT01635361 (http://clinicaltrials.gov/ct2/show/ NCT01635361). Current Controlled trials: Trial reference number ISRCTN 23560818 (http://www.controlled-trials. com/ISRCTN23560818/; DOI 10.1186/ISRCTN23560818). UK Clinical Research Network (UKCRN) study 12494 (http://public.ukcrn.org.uk/Search/StudyDetail.aspx?Study $\mathrm{ID}=12494)$.

Funding Department of Health Policy Research Programme.

\section{Key Points for Decision Makers}

The New Medicine Service (NMS) appears effective and cost effective compared with normal practice.

Increased patient adherence to their new medicine translated into increased health gain at reduced overall cost that is well below most accepted thresholds for technology implementation.

This is a simple intervention which has been popular with community pharmacists and patients, and is transferable into most therapeutic areas.

Consideration should be given to extending and evaluating the NMS in other potentially beneficial areas, and these results are likely to be transferable into health systems less integrated than the UK NHS.

\section{Introduction}

Adherence to medication is defined as the extent to which individuals take their medication as prescribed [1]. Nonadherence is commonly reported in key prevalent diseases such as chronic obstructive pulmonary disease (COPD): 33\% [2]; schizophrenia: 52\% [3]; asthma: 67\% [4]; and diabetes mellitus: 78\% [5]. Non-adherence causes reduced quality of life, increased hospitalisations and premature deaths [5-7]. A recent estimate sets the global economic impact at US $\$ 285$ billion, $57 \%$ of the economic impact of suboptimal medicines use [8]. Estimated opportunity cost to the English National Health Service (NHS England) of health gains foregone because of non-adherence is over $£ 930$ million per annum in just five diseases [9]: asthma, type 2 diabetes, high cholesterol/coronary heart disease, hypertension and schizophrenia. Improving adherence from current levels to $80 \%$ across these five areas would save the NHS $£ 500$ million per annum [9].

One effective way to improve adherence focuses on patients who receive a new medicine for a long-term condition, as they often experience problems that can quickly lead to a proportion becoming non-adherent over time $[10,11]$. Barber et al. developed an intervention with a theoretical basis in the self-regulatory model (SRM) [10, 12], designed to elicit patients' experiences with, and concerns about, their new medicine. This intervention significantly reduced non-adherence and was cost effective [13, 14]. Its approach was adopted as government policy [15] and in adapted form was launched as the national New Medicine Service (NMS) in 2011 [15] for people starting a new medicine for asthma/COPD, type 2 diabetes, hypertension or antiplatelet/anticoagulant treatment [16]. The design differs from the original intervention as there are four specified patient groups associated with high rates of avoidable hospital admissions. The original intervention was delivered via a centralised telephone service, whereas NMS is delivered by community pharmacists providing the medicine, either faceto-face or over the telephone. Accredited pharmacies provide NMS, are remunerated for each episode of care and have guidance on how to conduct the intervention [16]. Of 11,495 community pharmacies in England, 10,553 (91.2\%) had delivered the NMS to at least one patient between November 2011 and January 2014 [17].

The aim of this study was to evaluate the cost effectiveness of the NMS compared with normal practice in changing medicine-taking behaviour, following published reporting criteria [18]. The incremental cost per extra quality-adjusted-life-year (QALY) generated was determined from the perspective of the funder (NHS England).

\section{Methods}

A randomised controlled trial (RCT) has assessed NMS effectiveness [19]. At 10 weeks, NMS significantly increased the proportion of patient-reported adherence by $10.2-70.7 \%$, compared with normal practice of $60.5 \%$ [20, 21]. Trial design precluded observation of long-term outcomes and costs from changes in adherence. Many benefits of improved adherence are delivered well into the future. Here, we simulated the effect of observed adherence increases on patient outcomes and NHS costs by designing economic models for each drug-disease pair. We developed this method previously in a cross-therapeutic intervention focused on medication errors [22]. Here, we combine the results from the NMS trial with projected harm from non-adherence to generate estimates of patient outcomes and NHS costs (Fig. 1). 


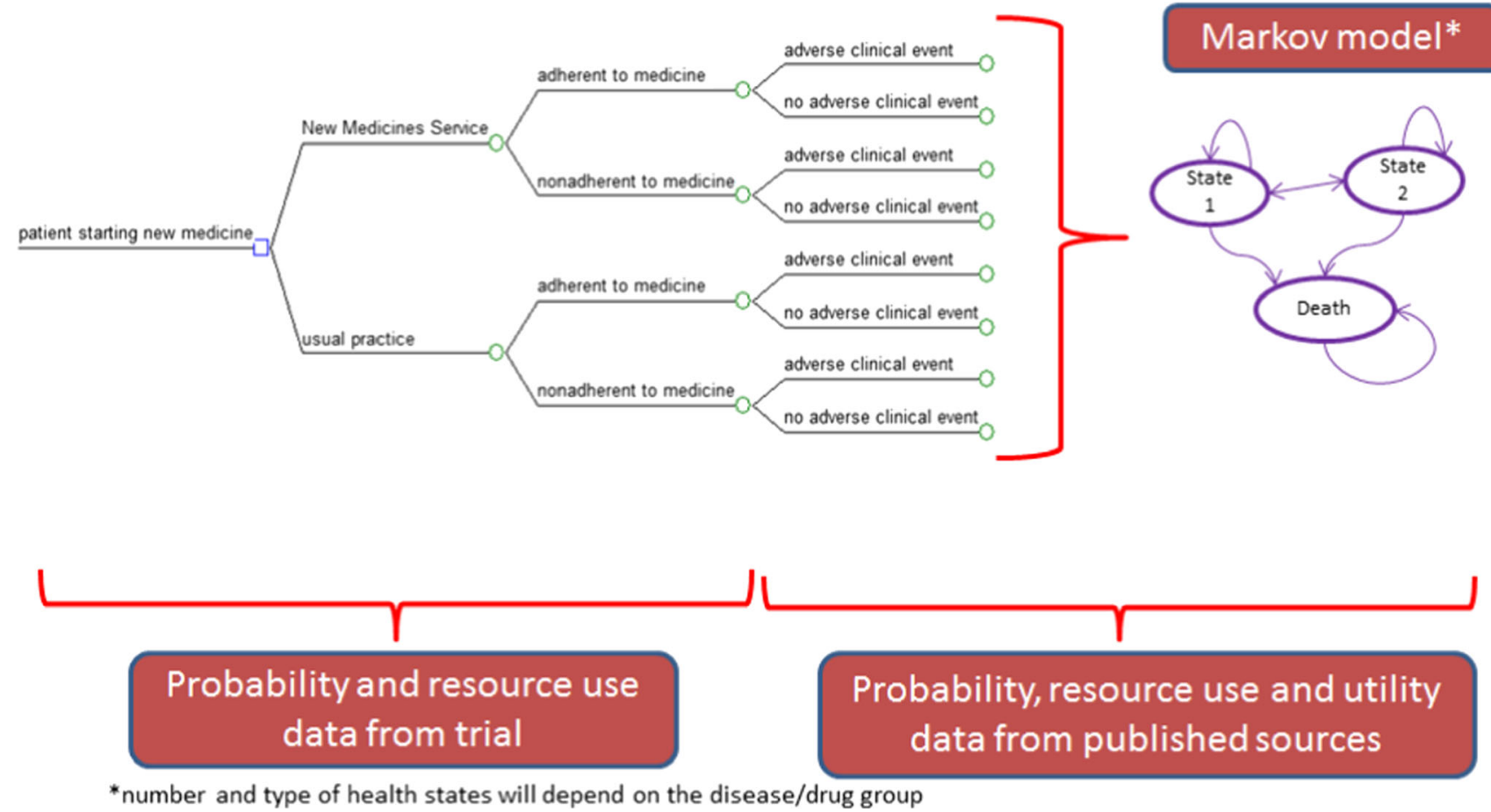

Fig. 1 Overview of economic model developed to combine New Medicine Service (NMS) trial results with estimates of harm caused by nonadherence

\subsection{Intervention and Comparators, Patient Characteristics and Outcomes}

\subsubsection{New Medicine Service (NMS) Intervention}

NMS begins with the patient's initial presentation with a prescription for a medicine that is new to them in a community pharmacy. Patients can be referred by their prescriber, self-refer, or the pharmacist can invite the patient to use the service. The intervention consists of a one-to-one consultation 7-14 days later, with a follow-up 14-21 days after that, the whole episode lasting 5 weeks. These are the points where the pharmacist asks about adherence. Outcomes were collected by researchers at 10 weeks.

The primary aim of the intervention, which can be faceto-face or telephone-based (in this study, all follow-up was via telephone) is the patient-centred identification of any problems with the treatment and provision of appropriate support or action [23]. Action may include referring the patient back to their prescriber (Fig. 2).

\subsubsection{Normal Practice}

Normal practice was the pharmacist's usual advice. There was no planned follow-up.

\subsubsection{Study Outcomes}

The RCT primary outcome was self-reported adherence at 10 weeks, considered the minimum time required to demonstrate behavioural change [13].

Patients were contacted by telephone by a researcher and asked about adherence behaviour using the question: "People often miss taking doses of their medicines, for a wide range of reasons. Have you missed any doses of your new medicine, or changed when you take it? (Prompt: when did you last miss a dose?)" [24]. This is the adherence question asked by pharmacists during the NMS intervention and follow-up. The patient was defined as nonadherent if any doses were missed without the advice of a medical professional in the previous 7 days.

Little validation has been carried out for most self-report adherence measures [25]. An existing scale, the Morisky Eight Item Medication Adherence Scale (MMAS-8), validated in hypertension, was used to support our primary outcome measure, and collected via self-completion postal questionnaire [26]. These results are available in [20].

Sample size was determined according to the primary outcome at 10 weeks (see electronic supplementary material and [19-21]). Sample characteristics and study outcomes are reported in Tables 1 and 2. The characteristics 
Fig. 2 New Medicine Service intervention

Table 1 Patient and pharmacy characteristics by treatment arm

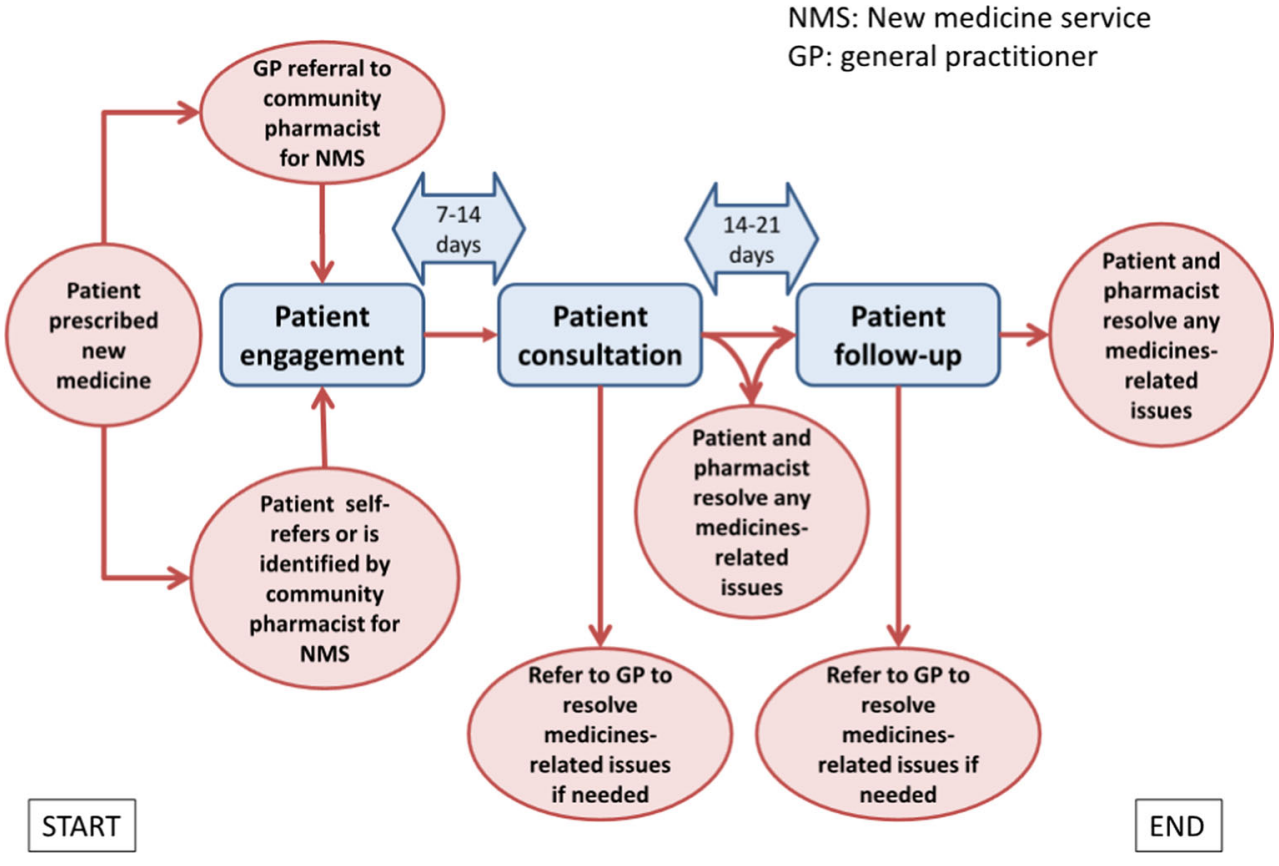

NMS: New medicine service

GP: general practitioner

\begin{tabular}{lll}
\hline Patient characteristics & Normal practice & New Medicine Service \\
\hline Total & 253 & 251 \\
Antiplatelet/anticoagulant $(n=43,8.5 \%)$ & $19(7.5)$ & $24(9.6)$ \\
Asthma/COPD $(n=117,23.2 \%)$ & $58(22.9)$ & $59(23.5)$ \\
Hypertension $(n=249,49.4 \%)$ & $128(50.6)$ & $121(48.2)$ \\
Type 2 diabetes $(n=95,18.8 \%)$ & $48(19.0)$ & $47(18.7)$ \\
Female $(n=260,51.6 \%)$ & $135(53.4)$ & $125(49.8)$ \\
Age of total cohort (year) $n ;$ mean $(\mathrm{SD})$ & $253 ; 59.3(15.0)$ & $251 ; 59.5(15.3)$ \\
Total withdrawals by week $10 ; n(\%)$ & $37(14.6)$ & $16(6.4)$ \\
Economic deprivation based on IMD rank ${ }^{\mathrm{a}} ;$ mean $(\mathrm{SD})$ & \\
Pharmacy study sites & $10,241.5(8117.2)$ & $9880.0(7723.0)$ \\
Study patients & $13,708.3(8546.4)$ & $14,325.5(8906.8)$ \\
\hline
\end{tabular}

$C O P D$ chronic obstructive pulmonary disease, $n$ number, $S D$ standard deviation

${ }^{a}$ IMD: Index of Multiple Deprivation (rank)—each area of England is ranked based on its economic deprivation score. The most deprived area of England is ranked 1. The rank only indicates relative position and does not provide a quantifiable comparison. An area ranked 50 is not twice as deprived as the area ranked 100 (English deprivation rank scores range from 1 to 32482)

(age, sex, ethnicity, disease area) of the RCT cohort were very similar to the population accessed from the national PharmOutcomes records of 451,222 NMS consultations recorded from October 2011 to 2 December 2013 [20]. With regards to economic deprivation, the median Index of Multiple Deprivation (IMD) rank for England is 16,241, indicating that our study population is slightly more deprived than average.

\subsubsection{Intervention and Within-Trial Costs}

Costs comprised patient-level intervention costs and healthcare contact over the 10-week follow-up period. Subsequent resource use at follow-up was obtained from patient diaries, 116 normal practice and 122 NMS, consisting of NHS (primary care, secondary care, allied health professionals) and non-NHS costs (community-based 
Table 2 Adherence results for NMS and normal practice measured using NMS question and MMAS-8 at 10 weeks

\begin{tabular}{lllll}
\hline ITT $^{\mathrm{a}}$ at 10 weeks & $\begin{array}{l}\text { Unadjusted probability } \\
(95 \% \mathrm{CI})^{\mathrm{b}}\end{array}$ & $\begin{array}{l}\text { Unadjusted odds ratio }^{\mathrm{b}} \\
(95 \% \mathrm{CI})\end{array}$ & $\begin{array}{l}\text { Adjusted probability }_{(95 \% \mathrm{CI})^{\mathrm{c}}} \\
\text { Adherence NMS }(N=378)\end{array}$ & $\begin{array}{l}\text { Adjusted odds ratio }^{\mathrm{c}} \\
(95 \% \mathrm{CI})\end{array}$ \\
$\begin{array}{l}\text { Normal practice } \\
\text { NMS }\end{array}$ & $0.61(0.54-0.67)$ & $1.58(1.03-2.42) ; p=0.037$ & $0.63(0.55-0.70)$ & $1.67(1.06-2.62) ; p=0.027$ \\
Adherence MMAS-8 $(N=267)$ & & $0.74(0.67-0.81)$ & $1.62(1.04-2.53)^{\mathrm{d}} ; p=0.032$ \\
Normal practice & $0.59(0.51-0.67)$ & $1.74(1.04-2.90) ; p=0.036$ & $0.65(0.56-0.75)$ & $1.88(1.06-3.34) ; p=0.030$ \\
NMS & $0.72(0.64-0.80)$ & & $0.78(0.70-0.86)$ & $1.77(0.96-3.28)^{\mathrm{d}} ; p=0.068$ \\
\hline
\end{tabular}

CI confidence intervals, ITT intention to treat, MMAS-8 Morisky eight-item Medication Adherence Scale, NMS New Medicine Service

${ }^{a}$ The ITT cohort was defined as all patients within a randomisation arm with measured outcomes, or who were followed up to the end of the study

b Simple logistic regression model

c Multi-level logistic regression model adjusted for recruiting pharmacy, disease, age, sex and medication count (level 1: patient, level 2: pharmacy)

${ }^{\mathrm{d}}$ Model accounting for multiple imputation of missing data

practitioners and allied health professionals including community pharmacists). These data were combined with NHS reference costs [27] and Personal Social Services Research Unit (PSSRU) costs [28] (see electronic supplementary material) to derive patient-level total costs. Comparison between treatment arms at patient level was made using a two-sample $t$-test on the original dataset, or on a bootstrapped dataset, depending on the normality of the distribution of costs [29]. Mean (median, range) total NHS costs for patients in normal practice and NMS are $£ 261$ ( $£ 121,0-1669)$, and $£ 239$ (£135, 25-1483), respectively. There was a general trend to reduced NHS costs, statistically non-significant, for the NMS intervention: $-£ 21(95 \% \mathrm{CI}-59$ to $150 ; p=0.1281)$.

\subsection{Clinical and Economic Impact of Non- adherence}

Six Markov models were developed in TreeAge Pro (TreeAge Software Inc, One Bank Street, Williamstown, MA, 01267, USA). The most commonly prescribed medicine within the four NMS areas was used to inform a model representative of that disease group. Asthma and COPD were modelled separately due to the different natural history of the disease and impact of non-adherence. As hypertension represented over $50 \%$ of the cohort, two models were built to reflect the two most common medication groups prescribed: calcium channel blockers and angiotensin-converting enzyme (ACE) inhibitors-index NMS drugs for 34.4 and $24.1 \%$ of hypertensive patients, respectively.
The models were hypertension-amlodipine; hypertension-ramipril; asthma-inhaled corticosteroid (ICS)-beclometasone; COPD-tiotropium; diabetes-metformin; anticoagulants-aspirin. Each model had a lifetime horizon (until the age of 100), an annual (hypertension, diabetes, anticoagulant), monthly (COPD), or weekly (asthma) cycle length with half-cycle correction and the UK treasury recommended $3.5 \%$ discount rate for both costs and outcomes. Age-related mortality was included in each model.

Each model described the consequences of being adherent to the medicine, compared with non-adherence. Entry age, disease severity, drug prescribed and health status in the models were those in the RCT cohort.

\subsubsection{Sources of Data and Model Design}

Each model is described in detail in the electronic supplementary material. For all models apart from aspirin we utilised and adapted existing published models to optimise design (amlodipine [30], ramipril [31], beclometasone [32], tiotropium [33], metformin [34]). We derived the aspirin model structure from case-control studies analysing outcomes in large UK cohorts of patients with a first prescription of aspirin [35, 36].

\subsubsection{Literature Searches}

A literature search was conducted through Medline, Embase and Web of Science using treatment pathwayspecific search terms. Databases were searched to the end of 2013. References in English and limited to humans were 
included. After excluding duplicate records, studies were included if they examined issues on the incidence, prevalence, treatment or resource use of the consequences of non-adherence. Reference lists of the retrieved references were hand-searched.

\subsubsection{Transition Probabilities}

Data came preferentially from up-to-date UK sources that reflected the NMS trial patient characteristics. The quality of evidence varied for the different models. Data were taken from RCTs such as effect of calcium channel blockers [37] or ACE inhibitors [31] on major cardiovascular consequences in hypertension, and effects of inhaled steroids on asthma control [38]. Observational data were available to populate parts of the metformin and aspirin models. In the metformin model, transition probabilities are based on UKPDS68 equations [34], using data on 3642 (type 2 diabetes) patients from UKPDS (United Kingdom Prospective Diabetes Study) for whom annual data on potential risk factors were available [39]. In the aspirin model, data were taken from case-control studies analysing outcomes in large UK cohorts of patients with a first prescription of aspirin [35, 36]. Where no other primary sources were available, transition probabilities estimated in published models were used, such as transition probabilities for exacerbations in COPD [40].

\subsubsection{Identifying the Effect of Non-adherence on Outcomes}

Quality of evidence for the effect of non-adherence on outcomes varied widely. Where possible, data on the impact of non-adherence were taken from large long-term cohort studies, such as the impact of non-adherence to antihypertensive treatment on long-term cardiovascular outcomes for the amlodipine [41] and ramipril models [42], and for myocardial infarction/chronic heart disease death [35] and for stroke/transient ischemic attack [36] in the aspirin model. The effect of non-adherence in the metformin model was modelled via a higher level of $\mathrm{HbAlc}$ [43], which resulted in estimated higher probabilities of diabetes complications. We used data from a study analysing non-adherence to antidiabetic medications (using MMAS-8 [26]) and HbA1c level in 301 patients with diagnosed type 2 diabetes in the US [43], good adherence (MMAS-8 score $\geq 3$ ) was associated with $10 \%$ lower HbAlc $(p=0.0003)$.

Little data on the effect of non-adherence on asthma or COPD control was available. We derived the effect of nonadherence on asthma control from baseline data of the SIMPLE study (observational trial of community pharmacy intervention for asthma management), combining adherence to ICS assessed using prescription refill data in the previous 6 months and Asthma Control Test [44] (ACT, $0 \leq \mathrm{ACT} \leq 25)$ results [45]. The most relevant results about adherence in COPD were available from Vestbo et al. [7]. Based on the Toward a Revolution in COPD Health (TORCH) study [46], they reported that adherent patients had a $60 \%$ [hazard ratio (HR) $0.4 ; 95 \%$ CI $0.35-0.46$ ] lower risk of death and a $44 \%$ [relative risk (RR) 0.56 ; $95 \%$ CI $0.48-0.65$ ] lower rate of severe exacerbations [7]. We found no data to inform the effect of adherence on frequency of non-severe exacerbations, so assumed that the HR was equivalent to severe exacerbations.

\subsubsection{Health Status}

For the amlodipine, ramipril, metformin and aspirin models, utilities were based on EQ-5D data from the Health Survey for England (2003, 2006), adjusted for age, sex and disease status [47]. Asthma utilities were taken from an RCT of ICS, using the Asthma Quality of Life Questionnaire (AQLQ [48]) scores [49]. Utilities for the COPD model were derived from an RCT of tiotropium [33, 50].

\subsubsection{Resource Use and Unit Costs}

Resource-use data came preferentially from up-to-date UK sources of observation of clinical practice, with disaggregated resource-use data, to allow attachment of current unit prices. If possible, individual patient data were used, with associated measures of mean and variation. If these were not available, point estimates were used, with carefully specified deterministic ranges, and standard methods for allocating distributions to these data were used.

The probability, cost and utility data were assigned beta, gamma and beta distributions, respectively, and are summarised in Tables 3, 4 and 5. Costs are given in year 2014 values.

\subsection{Incremental Analysis}

In the base case, we applied probabilities of adherence to each model, estimated from 10 -week trial results, for the primary adherence outcome measure (Table 2). Adjusted probability of adherence in the NMS group was $74 \%$, probability of adherence in normal practice was $63 \%$, and the odds ratio (OR) (NMS vs normal practice) was 1.67 $(1.06-2.62 ; p=0.027)$. Adherence was assumed to stay the same in both arms over the time horizon of the model.

Each model was populated with probability, cost and health status data. This allowed the generation of the outcomes and costs in a cohort who were adherent, and in a 
Table 3 NHS and non-NHS costs for normal practice and NMS intervention

\begin{tabular}{|c|c|c|}
\hline Cost category & $\begin{array}{l}\text { Normal practice }(n=116) \\
\text { Mean cost } / £(n, \mathrm{SE})\end{array}$ & $\begin{array}{l}\text { NMS }(n=122) \\
\text { Mean cost } / £(n, \mathrm{SE})\end{array}$ \\
\hline Primary care total & $81.6(111,5.76)$ & $72.18(115,4.99)$ \\
\hline GP total & $67.7(100,5.26)$ & $60.94(105,4.34)$ \\
\hline GP contact & $59.21(95,4.35)$ & $57.13(98,4.36)$ \\
\hline GP home visit & $3.66(2,3.02)$ & $0.7(1,0.7)$ \\
\hline GP phone call & $4.83(19,1.11)$ & $3.11(13,0.93)$ \\
\hline Nursing total & $13.9(79,1.53)$ & $11.24(73,1.56)$ \\
\hline Nurse contact & $12.49(73,1.46)$ & $10.73(72,1.51)$ \\
\hline Nurse home visit & $0.92(3,0.60)$ & $0.38(2,0.28)$ \\
\hline Nurse phone call & $0.49(7,0.29)$ & $0.13(3,0.08)$ \\
\hline Secondary care total & $175.54(53,28.76)$ & $141.23(52,25.79)$ \\
\hline Outpatient & $98.85(47,16.42)$ & $91.2(46,16.19)$ \\
\hline Accident and emergency & $2.02(2,1.42)$ & $0.96(1,0.96)$ \\
\hline Day case & $63.01(17,16.00)$ & $49.08(13,16.62)$ \\
\hline Inpatient & $11.66(1,11.66)$ & $0(0,0)$ \\
\hline Allied HCPs (NHS) total ${ }^{\mathrm{a}}$ & $3.73(19,1.13)$ & $1.75(16,0.48)$ \\
\hline Allied HCP contact & $2.37(16,0.66)$ & $1.48(13,0.43)$ \\
\hline Allied HCP home visit & $1.27(3,0.77)$ & $0.15(1,0.15)$ \\
\hline Allied HCP phone call & $0.08(2,0.06)$ & $0.12(3,0.07)$ \\
\hline NMS intervention & 0 & 24.60 \\
\hline Total NHS cost & $260.87(114,30.23)^{*}$ & $239.66(121,26.61)$ \\
\hline Community-based practitioner total $^{\mathrm{b}}$ & $4.81(5,2.66)$ & $4.71(2,4.44)$ \\
\hline Community-based practitioner phone call & $0.08(2,0.06)$ & $0.08(1,0.08)$ \\
\hline Community-based practitioner contact & $0.14(1,0.14)$ & $0.27(1,0.27)$ \\
\hline Community-based practitioner home visit & $4.58(4,2.54)$ & $4.36(1,4.36)$ \\
\hline Allied HCPs non-NHS total & $7.4(54,0.99)$ & $8.69(64,1.04)$ \\
\hline Community pharmacist & $6.31(48,0.93)$ & $7.57(61,0.91)$ \\
\hline Other associated HCPs non-NHS ${ }^{\mathrm{c}}$ & $1.1(10,0.35)$ & $1.13(11,0.34)$ \\
\hline Total non-NHS cost & $12.21(56,2.86)$ & $13.4(65,4.5)$ \\
\hline
\end{tabular}

GP general practitioner, $H C P$ healthcare practitioner, $N H S$ National Health Service, NMS New Medicine Service, $S E$ standard error

* Mean difference in costs: $£ 21.11$ (95\% CI -59.01 to $100.24 ; p=0.1281$ )

a Allied HCPs (NHS) include podiatrists, phlebotomists

${ }^{\mathrm{b}}$ Community-based practitioners include social workers

c Allied HCPs (non-NHS) include dentists, opticians, chiropractors cohort who were non-adherent to the medicine. The adherence for each drug-disease pair at 10-week follow-up in the NMS and normal practice arms were combined with the appropriate disease-drug-specific model. Using these models, we generated the difference in patient outcome and costs between NMS and normal practice for each diseasedrug pair. Probabilistic estimates of costs and outcomes were derived, the analysis generating 5000 iterations, using Monte Carlo simulation for each disease-drug pair.

The incremental costs and outcomes associated with each disease-drug pair were incorporated additively into the economic model to allow derivation of the total incremental impact of the NMS intervention costs and outcomes for all six disease-drug pairs. At this point the NMS intervention costs were added.

Deterministic and probabilistic incremental economic analyses were carried out. The incremental cost-per-QALY generated by NMS over normal practice was calculated using the following equation:

$\left(\right.$ Cost $_{\mathrm{NMS}}-$ Cost $\left._{\text {Normalpractice }}\right) /\left(\mathrm{QALY}_{\mathrm{NMS}}-\mathrm{QAL} \mathrm{Y}_{\text {Normalpractice }}\right)$.

Utilising Microsoft Excel, we used 5000 Monte Carlo simulations to obtain the incremental cost-effectiveness 
Table 4 Summary of probabilities in the Markov models in the adherent and non-adherent groups for each of the six models (for full details of parameter derivation for each model, see electronic supplementary material, Table 16)

\begin{tabular}{ll}
\hline Parameter Estimate and source & Esta
\end{tabular}

1. Hypertension-amlodipine model

$\mathrm{P}$ [stroke for adherent patient]

$\mathrm{P}$ [MI/fatal CHD for adherent patient]

$\mathrm{P}$ [stroke for non-adherent patient]

$\mathrm{P}[\mathrm{MI} /$ fatal CHD for non-adherent patient $]$

Effect of non-adherence, HR

$\mathrm{P}$ [MI/CHD (non-fatal MI or fatal CHD) being fatal CHD]

$\mathrm{P}$ [stroke being fatal]

$\mathrm{P}$ [death for MI survivors]

$\mathrm{P}$ [death for stroke survivors]

$\mathrm{P}$ [death from all other causes]

2. Hypertension-ramipril model

P [fatal cardiovascular event (MI, stroke,coronary event, heart failure, other cardiovascular events, first events) for adherent patient]

$\mathrm{P}$ [fatal cardiovascular event for non-adherent patient]

P [non-fatal MI for adherent patient]

$\mathrm{P}$ [non-fatal stroke for adherent patient]

$\mathrm{P}$ [non-fatal MI for adherent patient]

$\mathrm{P}$ [non-fatal stroke for adherent patient]

$\mathrm{P}$ [death for MI survivors]

$\mathrm{P}$ [death for stroke survivors]

Effect of non-adherence, HR

$\mathrm{P}$ [death from all other causes]

3. Asthma-beclometasone model

P [successful control $\rightarrow$ sub-optimal control]

$\mathrm{P}$ [successful control $\rightarrow$ primary care exacerbation]

$\mathrm{P}$ [successful control $\rightarrow$ secondary care exacerbation]

$\mathrm{P}$ [sub-optimal control $\rightarrow$ successful control]

$\mathrm{P}$ [sub-optimal control $\rightarrow$ sub-optimal control]

$\mathrm{P}$ [sub-optimal control $\rightarrow$ primary care exacerbation]

$\mathrm{P}$ [sub-optimal control $\rightarrow$ secondary care exacerbation]

$\mathrm{P}$ [secondary care exacerbation $\rightarrow$ successful control]

$\mathrm{P}$ [secondary care exacerbation $\rightarrow$ sub-optimal control]

$\mathrm{P}$ [secondary care exacerbation $\rightarrow$ primary care exacerbation]

$\mathrm{P}$ [secondary care exacerbation $\rightarrow$ secondary care exacerbation]

$\mathrm{P}$ [death from all other causes]
Age- and sex-dependent risk from ASCOT study [30]

$\mathrm{P}$ [stroke for adherent patient] $\times$ effect of nonadherence (HR)

$\mathrm{P}$ [MI/fatal CHD for adherent patient $] \times$ effect of non-adherence (HR)

Intermediate vs high adherence: HR 1.39 [41]

Age- and sex-dependent risk from ASCOT study [30]

Age and sex dependent [73]

$0.0068[31]$

0.0083, P [fatal cardiovascular event for adherent patient] $\times$ effect of non-adherence (HR)

$0.0041[31]$

$0.0075[31]$

0.0050, P [non-fatal MI for adherent patient] $\times$ effect of non-adherence $(\mathrm{HR})$

$0.0092, \mathrm{P}$ [non-fatal stroke for adherent patient] $\times$ effect of non-adherence $(\mathrm{HR})$

Age, sex, number of years from MI dependent [74], personal communication

Age, sex, number of years from stroke dependent [75], personal communication

HR 0.81 (95\% CI 0.67-0.98), adjusted for age and sex (base-case scenario) [42]

Age and sex dependent [73]

$\begin{aligned} & \text { Adherent patients } \\ & {[38,76]}\end{aligned} \quad \begin{gathered}\text { Non-adherent patients } \\ {[38,76]}\end{gathered}$
$0.1563 \times(1-\mathrm{p})^{\mathrm{a}} \quad 0.3710 \times(1-\mathrm{p})[45]^{\mathrm{a}}$
$0.0135 \times(1-\mathrm{p})^{\mathrm{a}}$
$0.0054 \times(1-\mathrm{p})^{\mathrm{a}}$
$0.1394 \times(1-\mathrm{p})^{\mathrm{a}}$
$0.8322 \times(1-\mathrm{p})^{\mathrm{a}}$
$0.0174 \times(1-\mathrm{p})^{\mathrm{a}}$
$0.0109 \times(1-\mathrm{p})^{\mathrm{a}}$
$0.2000 \times(1-\mathrm{p})^{\mathrm{a}}$
$0.2000 \times(1-\mathrm{p})^{\mathrm{a}}$
$0.4000 \times(1-\mathrm{p})^{\mathrm{a}}$
$0.4000 \times(1-\mathrm{p})^{\mathrm{a}}$
Age and sex dependent [73]


Table 4 continued

\begin{tabular}{lcc}
\hline Parameter & Estimate and source \\
\hline 4. COPD-tiotropium model & & \\
Probability of exacerbation & $\begin{array}{c}\text { Adherent patients } \\
{[7,77]}\end{array}$ & $\begin{array}{c}\text { Non-adherent patients } \\
{[7,77]}\end{array}$ \\
& 0.051 & 0.089 \\
Moderate COPD $\rightarrow$ exacerbation & 0.097 & 0.165 \\
Moderate COPD $\rightarrow$ severe exacerbation given an exacerbation occurs & 0.075 & 0.129 \\
Severe COPD $\rightarrow$ exacerbation & 0.136 & 0.229 \\
Severe COPD $\rightarrow$ severe exacerbation given an exacerbation occurs & 0.096 & 0.164 \\
Very severe COPD $\rightarrow$ exacerbation & 0.192 & 0.316
\end{tabular}

Effect of non-adherence on exacerbations rate, HR

Effect of non-adherence on death rate, HR

$44 \%$ (HR 0.56; 95\% CI 0.48-0.65); lower rate of severe exacerbations for adherent patients [7]

$60 \%$ (HR 0.4; 95\% CI 0.35-0.46); lower risk of death for adherent patients [7]

$\mathrm{P}$ [moving between chronic health states ] year 1, subsequent years

\section{Diabetes-metformin model}

$\mathrm{P}$ [fatal first diabetes complication (MI, CHF, stroke, renal failure, amputation) for adherent patient]

$\mathrm{P}$ [fatal first diabetes complication for nonadherent patient]

[77]

Patient characteristic and HbA1c-dependent value from UKPDS68 [34] and UKPDS34 [39]

Age and sex dependent [73]

$\mathrm{HbA1c}$ multiplier for non-adherent patient: 1.105 (95\% CI 1.047-1.166)

HbA1c for non-adherent patient (age) $=\mathrm{HbA} 1 \mathrm{c}$ for adherent patient (age) $\times 1.105$ [43]

\section{Antiplatelets/anticoagulants-aspirin model}

$\mathrm{P}$ [event-free $\rightarrow$ non-fatal $\mathrm{MI}^{\mathrm{b}}$ ]

$\mathrm{P}$ [event-free $\rightarrow$ non-fatal stroke ${ }^{\mathrm{b}}$ ]

Adherent patient

Non-adherent patient

0.0056 0.0086 [35]

0.0019

$0.0028[36]$

$\mathrm{P}$ [event-free $\rightarrow$ fatal $\mathrm{MI} / \mathrm{CHD}^{\mathrm{b}}$ ]

0.0015

$0.0023[35]$

$\mathrm{P}$ [event-free $\rightarrow$ fatal stroke ${ }^{\mathrm{b}}$ ]

$\mathrm{P}$ [non-fatal MI $\rightarrow$ death]

$\mathrm{P}$ [non-fatal stroke $\rightarrow$ death]

$\mathrm{P}$ [death from all other causes]
0.0002

0.0003 [36]

Dependent on age, year after the first MI, sex [74]

Dependent on age, year after the first stroke, sex [75]

Age and sex dependent [73]

CHD coronary heart disease, $C H F$ congestive heart failure, $C I$ confidence intervals, $C O P D$ chronic obstructive pulmonary disease, $H b A l c$ glycosylated haemoglobin, $H R$ hazard ratio, IHD ischaemic heart disease, $M I$ myocardial infarction, $p$ probability, SE standard error, $U K P D S$ United Kingdom Prospective Diabetes Study

a Transition probabilities between asthma states from [76, 38] with mortality (P[death from all other causes]) incorporated $(p)$

b Probabilities for three age groups, 50-64 years, 65-74 and 75-84 years, respectively. Probabilities calculated from incidence rates reported. In the case of non-adherent patients, incident rates adjusted by the effect of non-adherence (reported rate ratios for events, comparing non-adherence vs adherence) 
Table 5 Summary of utilities and costs for the Markov models in the adherent and non-adherent groups for each of the six models (for full details of parameter derivation for each model, see electronic supplementary material, Table 17)

\begin{tabular}{|c|c|c|}
\hline Health state & Utility weights & Mean cost/patient ( $£ ; 2014$ values) \\
\hline \multicolumn{3}{|c|}{ 1. Hypertension-amlodipine } \\
\hline Well & Age- and sex-dependent, no cardiovascular event [47] & Mean annual cost of medication (amlodipine): $13.4[78,79]$ \\
\hline \multirow[t]{2}{*}{ Non-fatal MI } & Age- and sex-dependent + MI history & 1st year: 5704.6 \\
\hline & Utility decrement (MI) added [47] & $\geq 2$ nd year: $986.7[78-81]$ \\
\hline \multirow[t]{2}{*}{ Non-fatal stroke } & Age- and sex-dependent + stroke history & 1st year: 4161.8 \\
\hline & Utility decrement (stroke) added [47] & $\geq 2$ nd year: $770.9[78-81]$ \\
\hline \multicolumn{3}{|c|}{ 2. Hypertension-ramipril } \\
\hline Well & Age- and sex-dependent no cardiovascular event [47] & Mean annual cost of medication (ramipril): $95.8[78,79]$ \\
\hline \multirow[t]{2}{*}{ Non-fatal MI } & Age- and sex-dependent + MI history & 1st year: 5787 \\
\hline & Utility decrement (MI) [47] & $\geq 2$ nd year: 1069 \\
\hline \multirow[t]{2}{*}{ Non-fatal stroke } & Age- and sex-dependent + stroke history & 1st year: 4244 \\
\hline & Utility decrement (stroke) added [47] & $\geq 2$ nd year: 853 \\
\hline \multicolumn{3}{|c|}{ 3. Asthma-beclometasone } \\
\hline Successful control & $0.900[49,82]$ & $13.4[32,81]$ \\
\hline Sub-optimal control & $0.842[49,82]$ & $34.9[32,81]$ \\
\hline \multirow[t]{2}{*}{ Asthma exacerbation } & Primary care-managed: 0.57 & Primary care-managed: 105.6 \\
\hline & Hospital-managed: 0.33 [83] & Hospital-managed: $2013.1[76,81]$ \\
\hline \multicolumn{3}{|l|}{ 4. COPD-tiotropium } \\
\hline Moderate COPD & $0.787[84,85]$ & 46.53 per month $[86]$ \\
\hline Severe COPD & $0.750[84,85]$ & 79.32 per month $[86]$ \\
\hline Very severe COPD & $0.647[84,85]$ & 125.13 per month $[86]$ \\
\hline \multirow[t]{2}{*}{ COPD exacerbation } & Non-severe decrement: 0.01 & Non-severe: 75.97 \\
\hline & Severe decrement: $0.042[50,87]$ & Severe: 1372 [86] \\
\hline \multicolumn{3}{|l|}{ 5. Diabetes-metformin } \\
\hline Well & Age- and sex-dependent, no cardiovascular event [47] & Mean annual cost of medication (metformin): $8.05[78,79]$ \\
\hline $\begin{array}{l}\text { Other diabetes health } \\
\text { states }\end{array}$ & Utility decrement [88] & $\begin{array}{l}\text { Fatal event; non-fatal event } 1 \text { st year; non-fatal event } \geq 2 \text { nd } \\
\text { year }[81,88,89]\end{array}$ \\
\hline IHD & -0.090 & N/A; 2916.4; 963.8 \\
\hline MI & -0.055 & $1477.7 ; 5624.0 ; 926.0$ \\
\hline $\mathrm{CHF}$ & -0.108 & $3252.8 ; 3252.8 ; 1140.2$ \\
\hline Stroke & -0.164 & $4338.9 ; 3440.0 ; 650.1$ \\
\hline Amputation & -0.280 & $11,200.4 ; 11,200.4 ; 646.9$ \\
\hline Blindness & -0.074 & N/A; $1469.0 ; 622.0$ \\
\hline Renal failure & -0.263 & $32,452.5 ; 32,452.5 ; 32,452.5$ \\
\hline \multicolumn{3}{|c|}{ 6. Antiplatelets/anticoagulants-aspirin } \\
\hline Event-free & $\begin{array}{l}\text { Age- and sex-dependent }+ \text { utility decrement for MI/stroke } \\
\text { history }[35,47]\end{array}$ & $1510.9[35,47,79-82]$ \\
\hline Non-fatal MI & $\begin{array}{l}\text { Age- and sex-dependent }+ \text { utility decrement for MI [47] } \\
\text { [35] }\end{array}$ & $\begin{array}{l}\text { 1st year after MI: } 6662.5 \\
\geq 2 \text { nd year: } 1597.1[35,47,78-81]\end{array}$ \\
\hline Non-fatal stroke & $\begin{array}{l}\text { Age- and sex-dependent }+ \text { utility decrement for stroke } \\
{[36,47]}\end{array}$ & $\begin{array}{l}\text { 1st year after stroke: } 4593.5 \\
\geq 2 \text { nd year: } 1817.5[36,47,78-81]\end{array}$ \\
\hline
\end{tabular}

CHF congestive heart failure, COPD chronic obstructive pulmonary disease, IHD ischaemic heart disease, $M I$ myocardial infarction; N/A not applicable

ratio (ICER) distribution. Negative ICERs are difficult to interpret and often arise when one of the interventions is either 'dominant' (more effective, less costly) or 'dominated' (less effective, more costly). It is not possible to tell this from the ICER itself. We report the proportion of ICER estimates in each of the four quadrants 
of the cost-effectiveness plane. We present mean ICERs for all results, indicating for negative ICERs whether the intervention is dominant or dominated.

Cost-effectiveness acceptability curves (CEACs) [51] were constructed to express the probability that NMS is cost effective as a function of the decision maker's ceiling cost-effectiveness ratio $(\lambda)$ [52].

\subsection{Sensitivity Analysis}

Deterministic analysis was conducted using the MMAS-8 adherence measure, for which probabilities of adherence were 78 and $65 \%$ in the NMS and normal practice groups, respectively, with OR of 1.88 (1.06-3.34), (Table 2).

The deterministic analysis was repeated to determine the effect of reducing the effect size, by reducing the adherence in the NMS arm, keeping the probability of adherence in the current practice arm unchanged. The difference in adherence between NMS and normal practice that would be required to attain an ICER of $£ 20,000$ per QALY was determined.

The probabilistic analysis was repeated in the diseasespecific subgroups.

\subsection{Model Validation}

Validity testing (conceptual model, input data, assumptions, model outcomes) was carried out iteratively as part of the development of the model throughout the project, with general practice, clinical pharmacy and health economics experts on the project team and the independent advisory panel [53]. This was carried out as multiple "walkthroughs' and review of specific written summaries of model structure, inputs and outcomes. There is no comparable model of a cross-therapeutic intervention to assess adherence. However, cross validity of individual models was maximised by using published models to derive a model for each disease where possible. The computerised individual and composite models were developed by LT and GG and examined by RAE, who has built a composite model in a previous study. Models were only accepted if there were no illogical or illegal inputs or outputs.

\section{Results}

\subsection{Incremental Analysis}

Tables 6 and 7 summarise the lifetime costs and outcomes derived from each disease-drug-specific model, their relative contribution to the economic model, and the overall results for the incremental analysis of NMS versus normal practice.

NMS generated a mean of 0.04 more QALYs per patient than normal practice, at a mean reduced cost of $-£ 139$, with probabilistic means of 0.05 (95\% CI 0.00-0.13) and -£144 (95\% CI -769 to 73 ). Therefore, NMS dominates normal practice, with an ICER of -£3166 (probabilistic mean $£ 2638$ ). The probability that NMS dominates normal practice is 0.78 . NMS has a high probability (0.96) of cost effectiveness compared with normal practice at a willingness to pay of $£ 20,000$ for one QALY (see Figs. 3, 4).

\subsection{Sensitivity Analysis}

The results were robust to changing adherence outcome. When MMAS- 8 was used to estimate changes in adherence, the incremental QALY was 0.06, incremental cost was $-£ 164$, with an ICER of $-£ 2953$ (see electronic supplementary material). The threshold

Table 6 Results from individual models and incremental economic analysis of NMS versus normal practice: deterministic analysis

\begin{tabular}{|c|c|c|c|c|c|c|c|c|}
\hline \multirow[t]{2}{*}{ Model } & \multirow[t]{2}{*}{ Percentage of NMS cohort } & \multicolumn{2}{|c|}{ Mean cost $(\mathfrak{f})$} & \multicolumn{2}{|c|}{ Mean QALY } & \multicolumn{2}{|c|}{ Incremental } & \multirow[t]{2}{*}{ ICER (£/QALY) } \\
\hline & & $\mathrm{NMS}^{\mathrm{a}}$ & Normal practice & NMS & Normal practice & Cost $(\mathfrak{E})$ & QALY & \\
\hline Amlodipine & 25.3 & 1496.9 & 1512.0 & 14.22 & 14.17 & -15.1 & 0.04 & -338.0 \\
\hline Ramipril & 24.1 & 2925.4 & 2922.9 & 16.37 & 16.30 & 2.6 & 0.07 & 37.9 \\
\hline Aspirin & 8.5 & $22,881.6$ & $22,830.1$ & 10.04 & 10.03 & 51.5 & 0.01 & 5151.0 \\
\hline Beclometasone & 17.5 & $71,539.9$ & $72,432.2$ & 16.56 & 16.54 & -892.3 & 0.02 & $-44,614.0$ \\
\hline Tiotropium & 5.7 & $10,508.6$ & $10,250.3$ & 6.99 & 6.85 & 258.3 & 0.14 & 1845.2 \\
\hline Metformin & 18.8 & $15,285.7$ & $15,279.8$ & 9.55 & 9.53 & 5.9 & 0.02 & 293.0 \\
\hline Overall & 100 & $19,013.2$ & $19,151.8$ & 13.49 & 13.45 & -138.6 & 0.04 & -3166.1 \\
\hline
\end{tabular}

ICER incremental cost-effectiveness ratio, NMS New Medicine Service, $Q A L Y$ quality-adjusted life-year

${ }^{\text {a }}$ Incorporating cost of intervention equal to $£ 24.6$ 


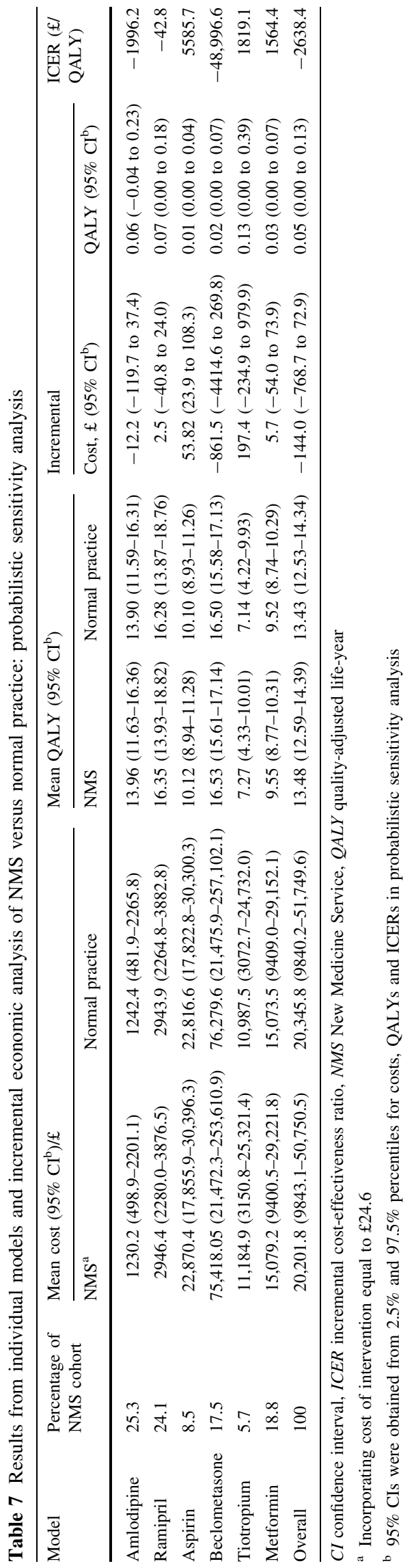

analysis demonstrated that the effect size of NMS compared with normal practice would need to be reduced to an OR of 1.01 to derive an ICER of $£ 20,000$ per QALY or above (see electronic supplementary material).

The disease-specific sensitivity analysis showed that if the NMS intervention targeted one of the disease areas only, NMS generated more QALY gain than normal practice in all models. NMS generated lower lifetime costs than normal practice for amplodipine-hypertension and asthma models. Higher costs in the NMS arm were generated for ramipril-hypertension, diabetes, COPD and aspirin models. In all cases, higher lifetime costs were the effect of reduced mortality for adherent patients (deaths from COPD exacerbations and from cardiovascular events). The mean ICERs were hypertension only (amlodipine plus ramipril): $-£ 115$; asthma only: $-£ 44,614$; COPD only: $£ 1845$; diabetes only: $£ 293$; aspirin only: $£ 5151$ (Table 8). Targeting individual disease areas with NMS has a probability over 0.90 of cost effectiveness compared with normal practice at a willingness to pay of $£ 20,000$ per QALY (Fig. 4).

\subsection{Model Validation}

Where possible, outputs from individual models were compared with published model outputs. The output of four of our individual models was comparable with published studies. The amlodipine model generated 14.3 QALYs in the adherent group, similar to another UK hypertension model [54] and a German model [55]. The ramipril model generated 16.6 QALYs in the adherent group, similar to another ACEI model [56]. The diabetes model generated 9.62 QALYs in the adherent group, similar to UKPDS68 [34]. The aspirin model generated 10.07 QALYs in the adherent group. There were no lifetime horizon models available for comparison, but a 10-year model generated 8.2-8.4 QALYs [57]. We were not able to find models with time horizons similar to our asthma and COPD models, so relied on feedback from clinical experts regarding model outcome validity.

\section{Discussion}

This economic evaluation suggests that NMS will deliver better patient outcomes than normal practice at overall reduced costs to the NHS in the long term. In the short term, extra costs incurred by remunerating community pharmacists were absorbed by small reductions in other NHS contact-related costs. 
Fig. 3 Incremental costeffectiveness plane: New Medicine Service (NMS) intervention versus normal practice. 5000 iterations in composite and medicinespecific models. In composite model, cost and QALY in NMS and normal practice arms are calculated as weighted cost and QALY from each medicinespecific model. Iterations were ordered by the index reflecting the strength of NMS effect (incorporating adherence effect from medicine-specific model and trial effect of NMS on adherence). $Q A L Y$ qualityadjusted life-year

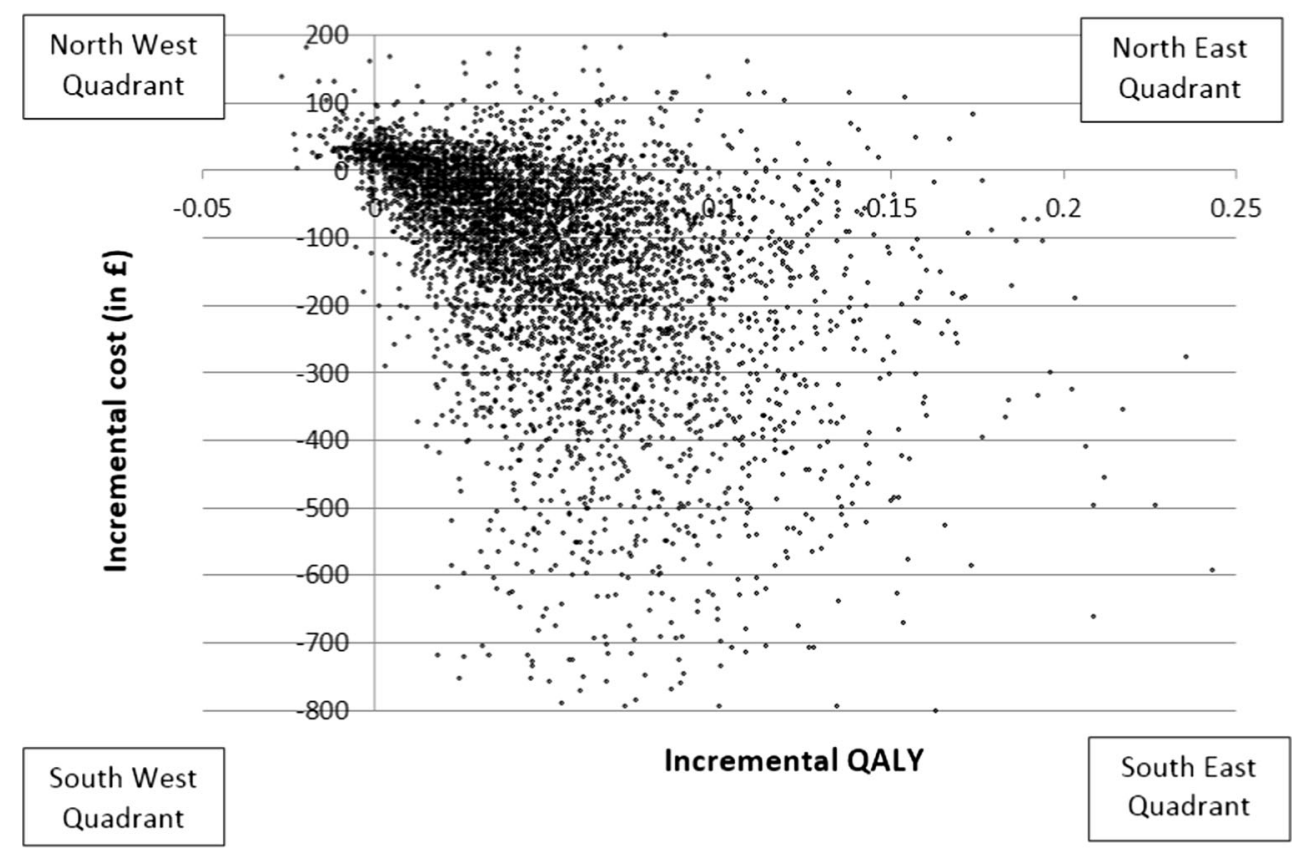

Fig. 4 Cost-effectiveness acceptability curve for New Medicine Service (NMS) intervention versus normal practice. This graph demonstrates the probability of cost effectiveness at a range of decision-maker ceiling willingness to pay for the NMS intervention overall. See electronic supplementary material (Section 4, Fig. 7) for Cost-effectiveness acceptability curves when only one disease group is considered at a time. $W T P$ willingness to pay

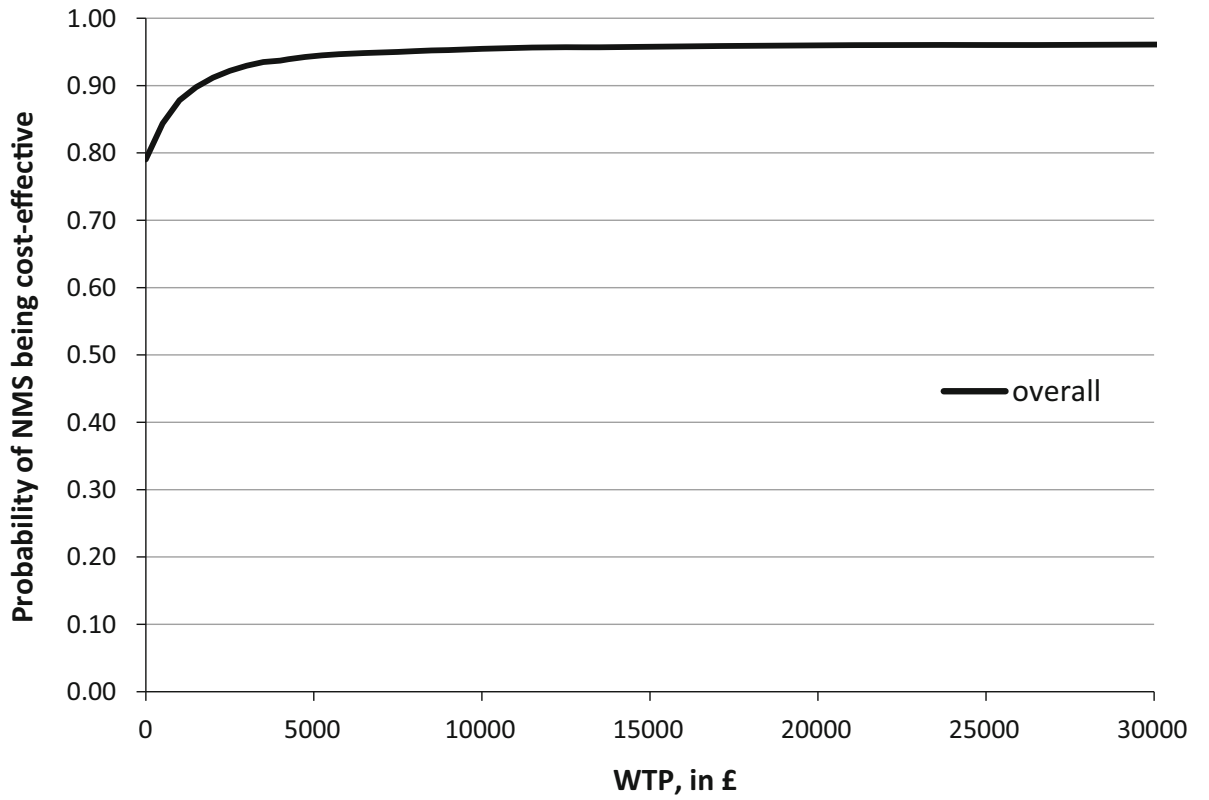

Interventions to improve adherence were assessed in a recent Cochrane review as "mostly complex and not very effective", and in need of better design [58]. Most strategies to improve medicines have been costly and atheoretical with little evidence of cost effectiveness [59, 60]. In contrast, NMS is an effective, relatively simple intervention with a strong theory base, transferable across diseases and healthcare settings, and which we estimate here to be cost effective for the NHS when compared with normal practice.

\subsection{Strengths and Limitations}

The current UK evaluative framework requires a cost per QALY to compare the value for money of different healthcare interventions. Patient adherence is an intermediate process indicator assumed to lead to changes in patient outcomes, but criticised as insufficient to demonstrate patient benefit [58]. Our analysis has moved beyond adherence, giving an estimate of clinical and economic 
Table 8 Incremental effectiveness analysis of NMS intervention versus current practice in specific disease groups (base-case adherence outcome)

\begin{tabular}{|c|c|c|c|c|c|c|c|c|}
\hline & \multicolumn{2}{|c|}{ Incremental } & \multirow[t]{2}{*}{ ICER, £/QALY } & \multicolumn{4}{|c|}{ \% ICERs in each quadrant } & \multirow{2}{*}{$\begin{array}{l}\text { Probability } \mathrm{C} / \mathrm{E} \\
\text { at } \lambda<£ 20 \mathrm{~K}\end{array}$} \\
\hline & Cost $/ £$ & $\overline{Q A L Y}$ & & $\mathrm{SE}^{\mathrm{a}}$ & $\mathrm{NE}$ & SW & NW & \\
\hline Base case & -138.6 & 0.04 & -3166.1 & 78.5 & 17.9 & 0.5 & 3.0 & 0.96 \\
\hline Hypertension only ${ }^{\mathrm{b}}$ & -6.5 & 0.06 & -115.5 & 46.9 & 47.1 & 0.0 & 6.0 & 0.93 \\
\hline Asthma only & -892.3 & 0.02 & $-44,614.0$ & 88.6 & 7.1 & 0.2 & 4.2 & 0.93 \\
\hline COPD only & 258.3 & 0.14 & 1845.2 & 13.1 & 84.3 & 1.1 & 1.5 & 0.97 \\
\hline Diabetes only & 5.9 & 0.02 & 293.0 & 40.7 & 57.2 & 0.0 & 2.1 & 0.97 \\
\hline Aspirin only & 51.5 & 0.01 & 5151.0 & 0.0 & 96.8 & 0.0 & 3.1 & 0.93 \\
\hline
\end{tabular}

$C / E$ cost effective, $C I$ confidence interval, $C O P D$ chronic obstructive pulmonary disease, ICER incremental cost-effectiveness ratio, $N M S$ New Medicine Service, $Q A L Y$ quality-adjusted life-year

${ }^{a}$ Probability of dominance

${ }^{\mathrm{b}}$ Probabilities of dominance are 50.0 and $36.2 \%$ and probabilities of cost effectiveness at $\lambda<£ 20,000$ are 83.7 and $98.0 \%$ for amlodipine and ramipril models, respectively. Probabilistic means with 95\% CI for hypertension patients are $-£ 4.5$ (95\% CI -69.4 to 28.4$)$ and 0.06 (95\% CI 0.01 to 0.20 ) for difference in costs and QALYs, respectively; ICER (£/QALY) was $-£ 39,236.1$ (95\% CI -4049.2 to 5096.9), with a median of $-£ 28.9$

impact of the intervention, and is an important development.

Pharmacist-led interventions often reflect their crosstherapeutic role around prescribing safety and patient adherence, bringing a significant challenge to the evaluative framework, which is historically disease-specific. Evaluations of pharmacist-led interventions often rely on generic process measures such as errors [61, 62], medication changes [63] or patient adherence [14], and tend to report ICERs such as cost per adherent patient or cost per error avoided [14, 61]; or utilise assumptions about the level of disutility incurred [64]. In a previous study examining the economic impact of a pharmacist-led information technology-based intervention (PINCER) to reduce medication errors in general practices, we developed a novel approach where economic models were developed for each of six errors, and generated a cost per QALY [22]. We applied this method in the economic evaluation of NMS. Therefore, this study differs from most other economic evaluations in this area, and we have been able to generate cost-per-QALY statistics to inform decision making.

The effect size of an absolute $10 \%$ improvement in adherence from normal practice to NMS is similar to that reported in the original work by Clifford [65]. Although the effect sizes here might initially be considered small, we anticipate significant benefits for two reasons. First, large numbers of patients have experienced the service. Second, we suggest that this is a conservative effect size, given probable patient recruitment bias, use of self-report of adherence, and the assumption that all the patients in the intervention arm actually received the NMS.
There is no gold standard for measuring patients' medicines adherence. Each approach has limitations. More than one adherence measure should be used to provide an internal check on validity [1]. In this study, we chose two self-report measures. Prescription filling was not an option for routine adherence monitoring in England due to lack of interoperability between community pharmacy and general practice systems. Although self-report tends to return a higher rate of medication adherence $(+15 \%)$ than some objective measures, it correlates with objective clinical measures [66]. It is possible to minimise biases through confidential interview [67], as is carried out as part of NMS; normalising non-adherence by recognising the challenges of taking regular medications; avoiding negative or positive questions which may encourage a biased response; and asking about a missed dose in the few days or a week prior to data collection rather than months or years [68].

A key limitation is the paucity of data upon which to base the estimates of economic impact of adherence in the individual disease-drug pairs, particularly the link between adherence and outcome. The wide range around the point estimates of cost effectiveness reflects the uncertainty in some of the individual adherence models.

Weaknesses in the models centre on assumptions made. It is assumed that the incremental effect of NMS compared with normal practice on adherence is the same over a patient's lifetime. Published estimates of persistence to new hypertension medicines at 1 year are around $48 \%$ [69, 70] and 51\% [71] dropping from 6-month rates of $65-68 \%$. This suggests that adherence is likely to drop in the cohort not having NMS at the beginning of their 
treatment. Our study suggests that the effect of NMS appears to be an absolute increase in adherence of $10 \%$ at 10 weeks post-initiation of the new medicine. It is not clear whether this effect will:

(a) disappear, such that there is no difference in adherence at 6 or 12 months;

(b) be maintained, such that adherence in both the NMS and control groups drops over time at the same rate, so the current benefit is maintained; or

(c) initiate a change in the patient's motivation or ability to adhere that leads to sustained adherence to the medicine such that the usual drop in adherence over time is prevented.

In the absence of any evidence to support which of these scenarios reflects reality, the economic analysis assumes scenario (b) for the basis of extrapolation of effect size. Sensitivity analysis suggested that the OR had to be reduced from 1.67 to 1.01 for NMS to stop being cost effective at a ceiling willingness to pay of $£ 20,000$ per QALY.

Apart from general limitations associated with the use of modelling, specific model limitations in our study include the use of the same effect of NMS on adherence for each disease-specific model since the trial was powered to analyse the effect of NMS in the entire NMS trial population. However, the effect of NMS on adherence may differ between disease groups and, in this case, the results of disease-specific models would be different than those assuming the same effect of NMS on adherence. The effects of adherence incorporated in the models were observed in the studies with different time horizons, from 1 year to longer (with maximal follow-up 4-5 years), while in the model we assume that effect of adherence is kept over a lifetime. We did not incorporate adverse event states in the models that may affect cost effectiveness (e.g. in older people, antihypertensive drugs may increase the risks of falls).

\subsection{Implications for Policy and Practice}

From inception of the NMS to the end of August 2016, 3.59 million consultations have been claimed for with over 820,000 in the year 2015/16 [90]. From the results of this economic evaluation, this suggests $£ 75.4$ million shortterm savings to the NHS, £517.6 million long-term cost savings to the NHS and 179,500 QALYs gained.

The research presented above suggests that the NMS is cost effective for each disease population than normal practice, with high (above 97\%) probability of cost effectiveness at a willingness to pay set at $£ 20,000$. On the basis of this evidence, it is recommended that this service continue to be commissioned in the future.
Where there is evidence suggesting therapeutic areas with significantly poor adherence, especially when nonadherence has significant effect on outcomes, consideration should be given to expanding the NMS. Potential areas might include conditions where medicines can have early adverse effects that subside over time such as antidepressants.

\section{Conclusions}

This study suggests increased health gain with NMS over normal practice at a cost per QALY well below most accepted thresholds for technology implementation [72]. This intervention could be extended to other groups of medicines. The findings are likely to have applicability to other healthcare systems, including those based on insurance.

\subsection{Data Availability Statement}

Several datasets were used for this analysis: (1) efficacy, patient-reported outcomes and healthcare resource utilisation data collected in the NMS randomised controlled trial (RCT). The patient-level data are not publicly available, but the results of the trials have been presented in several publications. The trial results supporting the findings of this analysis are available within the article and its electronic supplementary material. (2) The six individual models use RCT, observational data and estimation tools from multiple sources, for which references are provided in the article. (3) Cost data used in the model were obtained from referenced publicly available sources. (4) The model was developed in Data TreeAge and is not publicly available, but is available from the authors upon request.

Acknowledgements This study was commissioned and financed by the Department of Health. In addition, financial support was received from the Comprehensive Local Research Networks (CLRNs) to allow sites to receive service support costs as a result of participation in the study. The CLRNs involved included Trent, South Yorkshire, Leicester, Northamptonshire and Rutland (LNR) and the North Central London Research Consortium. Assistance with operationalising the study was provided by the Primary Care Research Networks. The study team expresses its gratitude to all of the study participants, the patients, the pharmacists and pharmacy companies and GPs, without whose participation this study would not have been possible. The study was monitored and supported by the independent NMS Evaluation Advisory Group (NEAG) chaired by Prof. Nick Mays, LSHTM. The study design and delivery was assisted by Dr. Tracey Thornley, Richard Harris, and Sara Garfield. Pharmacy recruitment was assisted by Dr. Tracey Thornley, Richard Harris, Mimi Lau (Numark), and Alistair Buxton (PSNC). Additional patient perspectives and review were provided by Ember Vincent and Clancy Williams. The study delivery was supported by Angela Wu, Rory Constable, Beatrice Odugbemi, Chris Macleod, Edward Lees-Manning, Julia Graichen, Katharine Wells, Lina Bader, Linda van 
Eikenhorst, Melanie Lynn, Oluwagbemileke Ojeleye, Stefanie Sickinger, Xiao-Jun Xu and Zoe Lim. Advice and support with data analysis was provided by Dr. Sarah Armstrong, Dr. Sarah Rodgers, Dr. Koen Putman, Dr. Anna Murphy and Dr. Amanj Baker. We would like to thank the following researchers for providing data used in the economic evaluation: Ramon Luengo-Fernandez, University Research Lecturer, Health Economics Research Centre, University of Oxford; Dr. Anna Murphy, Consultant Respiratory Pharmacist at University Hospitals of Leicester NHS Trust; Luis Alberto García Rodríguez, Director, CEIFE-Centro Español de Investigación Farmacoepidemiológica Madrid, Spain; Kate Smolina, Unit of Healthcare Epidemiology and British Heart Foundation Health Promotion Research Group, University of Oxford. Loraine Buck has been the NMS study administrator and has contributed significantly to the execution of all aspects of the research programme. Commissioned assistance was provided by Alison Taylor (transcriber), Alphagraphics-Peter Johnson (production of study diaries), Ambrow Ltd (study website), Graham Watson (database design), Marita Smith (transcriber), Kath's Keying Services Limited (transcriber) Petrina Salema (study logo design and web graphics). National data relating to NMS service provision was provided by Health Information Exchange (to March 2013) and by myhealthplace (from April 2013). The team are grateful to Prof. Donald E. Morisky, Department of Community Health Sciences, UCLA School of Public Health, for granting copyright permission to use the MMAS-8 adherence tool for this research. The University of Nottingham acted as the study sponsor and indemnifies the study. The team specifically wish to acknowledge the advice and support of Paul Cartledge, Angela Shone, Samantha Bateman and Kristy Angell.

Author contributions RAE designed and led the economic analysis, led drafting of the manuscript, was study principal investigator and contributed to the analysis of the RCT. LT designed and built the economic models, including collection of input data on transition probabilities, utilities and costs; carried out the economic analysis (including method and estimation of overall cost effectiveness); contributed to leading and design of the economic analysis; contributed to the COPD model; and contributed to the analysis of the RCT. GG designed and built the COPD model, including collection of input data on transition probabilities, utilities and costs; contributed to the economic analysis and carried out intervention and within-trial costing; and contributed to the analysis of the RCT. MJB led the delivery of the RCT including design of data collection tools and oversight of data collection. AJA contributed to model design and reviewed all models for clinical face validity. NB was involved in intervention design and costing and informed and reviewed the economic analysis for practice face validity. AL was involved in the delivery of the RCT and informed and reviewed the economic analysis for practice face validity. RM led the statistical design and analysis of the RCT and derived the estimates of effect for the economic evaluation. AC provided patient and public input to the project and interpretation of the economic evaluation. JW led the process evaluation of NMS and informed and reviewed the economic analysis for practice and policy relevance. All authors were involved in the drafting of the manuscript. Prof. RE is the guarantor and affirms that the manuscript is an honest, accurate and transparent account of the study being reported; that no important aspects of the study have been omitted; and that any discrepancies from the study as planned (and, if relevant, registered) have been explained.

\section{Compliance with Ethical Standards}

Ethical approval This report is independent research commissioned and funded by the Department of Health Policy Research Programme (Grant no. PR-IC-0711-10010) ('Understanding and Appraising the
New Medicines Service in the NHS in England'-PRP 029/0124). The views expressed in this publication are those of the authors and not necessarily those of the Department of Health. The RCT (ClinicalTrials.gov Trial reference number NCT01635361; http:// clinicaltrials.gov/ct2/show/NCT01635361) had full ethical approval.

Conflict of interest Rachel A. Elliott, Lukasz Tanajewski, Georgios Gkountouras, Anthony J. Avery, Nick Barber, Rajnikant Mehta, Matthew J. Boyd, Asam Latif, Antony Chuter and Justin Waring have completed the Unified Competing Interest form at http://www.icmje. org/coi_disclosure.pdf (available on request from the corresponding author) and declare no support from any organisation for the submitted work; no financial relationships with any organisations that might have an interest in the submitted work in the previous 3 years; and no other relationships or activities that could appear to have influenced the submitted work.

Open Access This article is distributed under the terms of the Creative Commons Attribution-NonCommercial 4.0 International License (http://creativecommons.org/licenses/by-nc/4.0/), which permits any noncommercial use, distribution, and reproduction in any medium, provided you give appropriate credit to the original author(s) and the source, provide a link to the Creative Commons license, and indicate if changes were made.

\section{References}

1. Horne R, Barber N, Weinman J, Elliott RA, Morgan M, Cribb A. Concordance, adherence and compliance in medicine taking: a scoping exercise. Report for the National Co-ordinating Centre for NHS Service Delivery and Organisation. London: R \& D; 2006. http://www.netscc.ac.uk/hsdr/files/project/SDO_FR_081412-076_V01.pdf. Accessed 10 June 2015.

2. Marsden E, Cubbin I, McAlavey A. An investigation into how poor compliance traditionally associated with corticosteroid therapy in asthma and chronic obstructive pulmonary disease can be improved to enhance long-term management and patient care. Int J Pharm Pract. 2009;17(S2):B55-6.

3. Llorca PM. Patient compliance in schizophrenia and the impact on patient outcome. Psychiatr Res. 2008;161:235-47.

4. Cerveri I, Locatelli F, Zoia MC, Corsico A, Accordini S, Marco R. International variations in asthma treatment compliance. Eur Respir J. 1999;14:288-94.

5. Ho PM, Rumsfeld JS, Masoudi FA, McClure DL, Plomondon ME, Steiner JF, et al. Effect of medication nonadherence on hospitalization and mortality among patients with diabetes mellitus. Arch Intern Med. 2006;166(17):1836-41.

6. Ho PM, Spertus JA, Masoudi FA, Reid KJ, Peterson ED, Magid DJ, et al. Impact of medication therapy discontinuation on mortality after myocardial infarction. Arch Intern Med. 2006;166(17):1842-7.

7. Vestbo J, Anderson JA, Calverley PM, Celli B, Ferguson GT, Jenkins $\mathrm{C}$, et al. Adherence to inhaled therapy, mortality and hospital admission in COPD. Thorax. 2009;64(11):939-43. doi:10.1136/thx.2009.113662.

8. IMS Institute for Healthcare Informatics. Advancing the responsible use of medicines: applying levers for change. USA: Parsipanny; 2012.

9. Trueman P, Lowson K, Blighe A, Meszaros A, Wright D, Glanville $\mathrm{J}$, et al. Evaluation of the scale, causes and costs of waste medicines. YHEC/London School of Pharmacy: London; 2010. https://core. ac.uk/download/pdf/111804.pdf. Accessed 10 June 2015. 
10. Barber N, Parsons J, Clifford S, Darracott R, Horne R. Patients' problems with new medication for chronic conditions. Qual Saf Health Care. 2004;13(3):172-5.

11. Ereshefsky L, Saragoussi D, Despiegel N, Hansen K, Francois C, Maman K. The 6-month persistence on SSRIs and associated economic burden. J Med Econ. 2010;13(3):527-36. doi:10.3111/ 13696998.2010.511050.

12. Leventhal H, Cameron LD. Behavioral theories and the problem of compliance. Patient Educ Couns. 1987;10:117-38.

13. Clifford S, Barber N, Elliott R, Hartley E, Horne R. Patientcentred advice is effective in improving adherence to medicines. Pharm World Sci. 2006;28(3):165-70.

14. Elliott RA, Clifford S, Barber N, Hartley E, Horne R. The cost effectiveness of a pharmacy advisory service to improve adherence to medicines. Pharm World Sci. 2008;30:17-23.

15. Department of Health. Pharmacy in England: Building on strengths-delivering the future http://www.dh.gov.uk/en/ Publicationsandstatistics/Publications/PublicationsPolicyAndGuidance/DH_083815. 2008. Accessed 12 Aug 2011.

16. Pharmaceutical Services Negotiating Committee. New Medicines Service. 2011. http://www.psnc.org.uk/pages/nms.html. Accessed 12 Aug 2011.

17. NHS Business Services Authority. Complete new medicines service (NMS) data. London. 2014. http://psnc.org.uk/servicescommissioning/advanced-services/nms/service-evaluation-nmsstatistics-andpharmoutcomes-data/. Accessed 10 June 2015.

18. Husereau D, Drummond M, Petrou S, Carswell C, Moher D, Greenberg D, et al. Consolidated health economic evaluation reporting standards (CHEERS) statement. Pharmacoeconomics. 2013;31(5):361-7. doi:10.1007/s40273-013-0032-y.

19. Boyd M, Waring J, Barber N, Mehta R, Chuter A, Avery A, et al. Protocol for the New Medicine Service Study: a randomized controlled trial and economic evaluation with qualitative appraisal comparing the effectiveness and cost effectiveness of the New Medicine Service in community pharmacies in England. Trials. 2013;14(1):411.

20. Elliott RA, Boyd M, Waring J, Barber ND, Mehta R, Chuter A et al. Understanding and Appraising the New Medicines Service in the NHS in England (029/0124)' A randomised controlled trial and economic evaluation with qualitative appraisal comparing the effectiveness and cost effectiveness of the New Medicine Service in community pharmacies in England. University of Nottingham. 2014.

21. Elliott RA, Boyd MJ, Salema N-E, Davies J, Barber N, Mehta $\mathrm{RL}$, et al. Supporting adherence for people starting a new medication for a long-term condition through community pharmacies: a pragmatic randomised controlled trial of the New Medicine Service. BMJ Qual Saf. 2015;. doi:10.1136/bmjqs-2015-004400.

22. Elliott RA, Putman KD, Franklin M, Annemans L, Verhaeghe N, Eden M, et al. Cost effectiveness of a pharmacist-led information technology intervention for reducing rates of clinically important errors in medicines management in general practices (PINCER). Pharmacoeconomics. 2014; doi:10.1007/s40273-014-0148-8.

23. Avery AJ, Rodgers S, Cantrill JA, Armstrong S, Cresswell K, Eden $\mathrm{M}$, et al. A pharmacist-led information technology intervention for medication errors (PINCER): a multicentre, cluster randomised, controlled trial and cost-effectiveness analysis. Lancet. 2012;379:1310-9. doi:10.1016/S0140-6736(11)61817-5.

24. Pharmaceutical Services Negotiating Committee, NHS Employers. NHS community pharmacy contractual framework 2011/12 service developments-latest information. August 2011.

25. Garfield S, Clifford S, Eliasson L, Barber N, Willson A. Suitability of measures of self-reported medication adherence for routine clinical use: a systematic review. BMC Med Res Methodol. 2011;11:149. doi:10.1186/1471-2288-11-149.
26. Morisky DE, Ang A, Krousel-Wood M, Ward HJ. Predictive validity of a medication adherence measure in an outpatient setting. J Clin Hypertens. 2008;10:348-54.

27. National Health Service Executive. NHS reference costs 2012-13. 2013. https://www.gov.uk/government/publications/ nhs-reference-costs-2012-to-2013. Accessed 20 June 2014.

28. Personal Social Services Research Unit (PSSRU). Unit Costs of Health and Social Care. 2012. http://www.pssru.ac.uk/projectpages/unit-costs/2012/. Accessed 20 June 2014.

29. Briggs A, Gray A. The distribution of health care costs and their statistical analysis for economic evaluation. J Health Serv Res Policy. 1998;3(4):233-45.

30. Lindgren P, Buxton M, Kahan T, Poulter NR, Br DahlÃf, Sever PS, et al. The lifetime cost effectiveness of amlodipine-based therapy plus atorvastatin compared with atenolol plus atorvastatin, amlodipine-based therapy alone and atenolol-based therapy alone: results from ASCOT1. Pharmacoeconomics. 2009;27(3):221-30.

31. Wing LMH, Reid CM, Ryan P, Beilin LJ, Brown MA, Jennings GLR, et al. A comparison of outcomes with angiotensin-converting - enzyme inhibitors and diuretics for hypertension in the elderly. N Engl J Med. 2003;348(7):583-92. doi:10.1056/NEJMoa021716.

32. Steuten L, Palmer S, Vrijhoef B, Van Merode F, Spreeuwenberg C, Severens H. Cost-utility of a disease management program for patients with asthma. Int $\mathrm{J}$ Technol Assess Health Care. 2007;23(2):184-91.

33. Price D, Asukai Y, Ananthapavan J, Malcolm B, Radwan A, Keyzor I. A UK-based cost-utility analysis of indacaterol, a oncedaily maintenance bronchodilator for patients with COPD, using real world evidence on resource use. Appl Health Econ Health Policy. 2013;11(3):259-74. doi:10.1007/s40258-013-0021-5.

34. Clarke PM, Gray AM, Briggs A, Farmer AJ, Fenn P, Stevens RJ, et al. A model to estimate the lifetime health outcomes of patients with Type 2 diabetes: the United Kingdom prospective diabetes study (UKPDS) outcomes Model (UKPDS no. 68). Diabetologia. 2004;47(10):1747-59. doi:10.1007/s00125-004-1527-z.

35. Rodríguez LAG, Cea-Soriano L, Martín-Merino E, Johansson S. Discontinuation of low dose aspirin and risk of myocardial infarction: case-control study in UK primary care. BMJ. 2011;. doi:10.1136/bmj.d4094.

36. Garcia Rodriguez LA, Cea Soriano L, Hill C, Johansson S. Increased risk of stroke after discontinuation of acetylsalicylic acid: A UK primary care study. Neurology. 2011;76(8):740-6.

37. Dahlöf B, Sever PS, Poulter NR, Wedel H, Beevers DG, Caulfield $\mathrm{M}$, et al. Prevention of cardiovascular events with an antihypertensive regimen of amlodipine adding perindopril as required versus atenolol adding bendroflumethiazide as required, in the Anglo-Scandinavian Cardiac Outcomes Trial-Blood Pressure Lowering Arm (ASCOT-BPLA): a multicentre randomised controlled trial. Lancet. 2005;366(9489):895-906. doi:10.1016/ S0140-6736(05)67185-1.

38. Kavuru M, Melamed J, Gross G, Laforce C, House K, Prillaman $\mathrm{B}$, et al. Salmeterol and fluticasone propionate combined in a new powder inhalation device for the treatment of asthma: a randomized, double-blind, placebo-controlled trial. J Allergy Clin Immunol. 2000;105(6 Pt 1):1108-16.

39. UK Prospective Diabetes Study. UKPDS) Group. Effect of intensive blood-glucose control with metformin on complications in overweight patients with type 2 diabetes (UKPDS 34. Lancet. 1998;352(9131):854-65.

40. Oostenbrink JB, Rutten-van Mölken MPMH, Monz BU, FitzGerald JM. Probabilistic markov model to assess the costeffectiveness of bronchodilator therapy in COPD patients in different countries. Value Health. 2005;8(1):32-46. doi:10.1111/ j.1524-4733.2005.03086.x. 
41. Mazzaglia G, Ambrosioni E, Alacqua M, Filippi A, Sessa E, Immordino $\mathrm{V}$, et al. Adherence to antihypertensive medications and cardiovascular morbidity among newly diagnosed hypertensive patients. Circulation. 2009;120(16):1598-605. doi:10.1161/ circulationaha.108.830299.

42. Nelson R, Reid CM, Ryan P, Willson K, Yelland L. Self-reported adherence with medication and cardiovascular disease outcomes in the Second Australian National Blood Pressure Study (ANBP2). Med J Aust. 2006;185:487-9.

43. Krapek K, King K, Warren SS, George KG, Caputo DA, Mihelich K, et al. Medication adherence and associated hemoglobin A1c in type 2 diabetes. Ann Pharmacother. 2004;38(9):1357-62. doi:10.1345/aph.1D612.

44. Quality Metric. The asthma control test. GlaxoSmithKline. 2012. http://www.asthmacontroltest.com/. Accessed 15 Mar 2012.

45. Murphy AL. The community pharmacy SIMPLE approach to asthma management. Regional Innovation Fund (RIF) Project Evaluation Report. 2012.

46. Vestbo J. The TORCH (towards a revolution in COPD health) survival study protocol. Eur Respir J. 2004;24(2):206-10.

47. Ara R, Brazier J. Health related quality of life by age, gender and history of cardiovascular disease: results from the Health Survey for England. Discussion Paper: Universities of York, Sheffield, Leeds. 2009.

48. Juniper E, Guyatt G, Ferrie P, King D. Development and validation of a questionnaire to measure asthma control. Eur Respir J. 1999;14(4):902-7.

49. Bateman ED, Bousquet J, Keech ML, Busse WW, Clark TJH, Pedersen SE, et al. The correlation between asthma control and health status: the GOAL study. Eur Respir J. 2007;29(1):56-62. doi:10.1183/09031936.00128505.

50. Rutten-van Mölken MMH, Hoogendoorn M, Lamers L. Holistic preferences for 1-year health profiles describing fluctuations in health. Pharmacoeconomics. 2009;27(6):465-77. doi:10.2165/ 00019053-200927060-00003.

51. Fenwick E, Byford S. A guide to cost-effectiveness acceptability curves. Br J Psychiatry. 2005;187(2):106-8. doi:10.1192/bjp.187. 2.106.

52. Fenwick E, Claxton K, Sculpher MJ. Representing uncertainty: the role of cost effectiveness acceptability curves. Health Econ. 2001;10:779-87.

53. Vemer P, Corro Ramos I, van Voorn GA, Al MJ, Feenstra TL. AdViSHE: a validation-assessment tool of health-economic models for decision makers and model users. Pharmacoeconomics. 2016;34(4):349-61. doi:10.1007/s40273-015-0327-2.

54. Montgomery AA, Fahey T, Ben-Shlomo Y, Harding J. The influence of absolute cardiovascular risk, patient utilities, and costs on the decision to treat hypertension: a Markov decision analysis. J Hypertens. 2003;21(9):1753-9. doi:10.1097/01.hjh. 0000084708.87421.d1.

55. Gandjour A, Stock S. A national hypertension treatment program in Germany and its estimated impact on costs, life expectancy, and cost-effectiveness. Health Policy. 2007;83(2-3):257-67. doi:10.1016/j.healthpol.2007.01.003.

56. Nordmann AJ, Krahn M, Logan AG, Naglie G, Detsky AS. The cost effectiveness of ACE inhibitors as first-line antihypertensive therapy. Pharmacoeconomics. 2003;21(8):573-85.

57. Lamotte M, Annemans L, Evers T, Kubin M. A multi-country economic evaluation of low-dose aspirin in the primary prevention of cardiovascular disease. Pharmacoeconomics. 2006;24(2):155-69.

58. Nieuwlaat R, Wilczynski N, Navarro T, Hobson N, Jeffery R, Keepanasseril A, et al. Interventions for enhancing medication adherence. Cochrane Database Syst Rev. 2014. doi:10.1002/ 14651858.CD000011.pub4.
59. Elliott RA, Barber N, Horne R. Cost-effectiveness of adherenceenhancing interventions: a quality assessment of the evidence. Ann Pharmacother. 2005;39:508-15.

60. National Institute for Health and Clinical Excellence. Medicines adherence: involving patients in decisions about prescribed medicines and supporting adherence. Clinical Guidelines: CG76. 2009.

61. Avery AJ, Rodgers S, Cantrill JA, Armstrong S, Cresswell K, Eden $\mathrm{M}$, et al. A pharmacist-led information technology intervention for medication errors (PINCER): a multicentre, cluster randomised, controlled trial and cost-effectiveness analysis. Lancet. 2012;379(9823):1310-9.

62. Klopotowska JE, Kuiper R, van Kan HJ, de Pont AC, Dijkgraaf MG, Lie AHL, et al. On-ward participation of a hospital pharmacist in a Dutch intensive care unit reduces prescribing errors and related patient harm: an intervention study. Crit Care (London, England). 2010;14(5):R174.

63. Denneboom W, Dautzenberg MGH, Grol R, De Smet PAGM. Treatment reviews of older people on polypharmacy in primary care: Cluster controlled trial comparing two approaches. Br J Gen Pract. 2007;57(542):723-31.

64. Karnon J, Campbell F, Czoski-Murray C. Model-based cost-effectiveness analysis of interventions aimed at preventing medication error at hospital admission (medicines reconciliation). J Eval Clin Pract. 2009;15:299-306.

65. Clifford S. Evaluation of a patient-centred, pharmacist-delivered intervention to improve patients' adherence to medication. Psychol Health. 2005;20:48-9.

66. Murri R, Ammassari A, Gallicano K, Luca AD, Cingolani A, Jacobson D, et al. Patient-reported nonadherence to HAART is related to protease inhibitor levels. J Acquir Immune Defic Syndr. 2000;24(2):123-8.

67. Butler JA, Peveler RC, Roderick P, Horne R, Mason JC. Measuring compliance with drug regimens after renal transplantation: comparison of self-report and clinician rating with electronic monitoring. Transplantation. 2004;77(5):786-9.

68. Lehmann A, Aslani P, Ahmed R, Celio J, Gauchet A, Bedouch P, et al. Assessing medication adherence: options to consider. Int $\mathrm{J}$ Clin Pharm. 2014;36(1):55-69. doi:10.1007/s11096-013-9865-x.

69. Caro JJ, Salas M, Speckman JL, Raggio G, Jackson JD. Persistence with treatment for hypertension in actual practice. Can Med Assoc J. 1999;160(1):31-7.

70. Vrijens B, Vincze G, Kristanto P, Urquhart J, Burnier M. Adherence to prescribed antihypertensive drug treatments: longitudinal study of electronically compiled dosing histories. BMJ. 2008;336(7653):1114-7. doi:10.1136/bmj.39553.670231.25.

71. Morgan SG, Yan L. Persistence with hypertension treatment among community-dwelling BC seniors. Can J Clin Pharmacol. 2004;11(2):e267-73.

72. McCabe C, Claxton K, Culyer AJ. The NICE cost-effectiveness threshold: what it is and what that means. Pharmacoeconomics. 2008;26(9):733-44.

73. Office for National Statistics. Mortality rates UK 2009-2010. 2012. http://www.ons.gov.uk/ons/taxonomy/search/index. html?nscl=Life + Tables\&nscl-orig=Life + Tables\&content-type $=$ Dataset $\&$ content-type $=$ Reference + table $\&$ sortDirection $=$ DES CENDING\&sortBy=pubdate. Accessed 10 June 2015.

74. Smolina K, Wright FL, Rayner M, Goldacre MJ. Long-term survival and recurrence after acute myocardial infarction in England, 2004 to 2010. Circ Cardiovasc Qual Outcomes. 2012. doi:10.1161/circoutcomes.111.964700.

75. Luengo-Fernandez R, Gray AM. Rothwell PM, null. A population-based study of hospital care costs during 5 years after transient ischemic attack and stroke. Stroke J Cereb Circ. 2012;43(12):3343-51. 
76. Price MJ, Briggs AH. Development of an economic model to assess the cost effectiveness of asthma management strategies. Pharmacoeconomics. 2002;20(3):183-94.

77. Rutten-van Mölken MMH, Oostenbrink J, Miravitlles M, Monz B. Modelling the 5-year cost effectiveness of tiotropium, salmeterol and ipratropium for the treatment of chronic obstructive pulmonary disease in Spain. Eur $\mathrm{J}$ Health Econ. 2007;8(2):123-35. doi:10.1007/s10198-007-0039-4.

78. Pharmaceutical Services Negotiating Committee. Evaluation of Evidence Provided by PharmOutcomes New Medicines Service Data. 2013.

79. British Medical Association, Royal Pharmaceutical Society of Great Britain. British National Formulary 66th Edition. September (66) ed. London: BMJ Group and RPS Publishing. 2013.

80. Lindgren P, Buxton M, Kahan T, Poulter NR, Dahlöf B, Sever PS, et al. Economic evaluation of ASCOT-BPLA: antihypertensive treatment with an amlodipine-based regimen is cost effective compared with an atenolol-based regimen. Heart. 2008;94(2):e4. doi:10.1136/hrt.2007.127217.

81. Department of Health. HSHC 2013. Health service cost index, annual summaries. 2013. http://www.info.doh.gov.uk/doh/ finman.nsf/Newsletters?OpenView\&Start=13.1\&ExpandView. Accessed 10 June 2015

82. Briggs AH, Bousquet J, Wallace MV, Busse WW, Clark TJH, Pedersen SE, et al. Cost-effectiveness of asthma control: an economic appraisal of the GOAL study. Allergy. 2006;61(5):531-6. doi:10.1111/j.1398-9995.2006.01038.x.

83. Lloyd A, Price D, Brown R. The impact of asthma exacerbations on health-related quality of life in moderate to severe asthma patients in the UK. Prim Care Respir J. 2007;16(1):22-7.
84. Rutten-van Mölken MPMH, Oostenbrink JB, Tashkin DP, Burkhart D, Monz BU. Does quality of life of copd patients as measured by the generic euroqol five-dimension questionnaire differentiate between copd severity stages? Chest. 2006;130(4):1117-28. doi:10.1378/chest.130.4.1117.

85. Dolan P, Gudex C, Kind P, Williams A. A social tariff for EuroQol: results from a UK general population survey: Centre for Health Economics, University of York; 1995.

86. Hertel N, Kotchie RW, Samyshkin Y, Radford M, Humphreys S, Jameson K. Cost-effectiveness of available treatment options for patients suffering from severe COPD in the UK: a fully incremental analysis. Int J Chronic Obstr Pulm Dis. 2012;7:183-99. doi:10.2147/copd.s29820.

87. Hettle R, Wouters H, Ayres J, Gani R, Kelly S, Lion M, et al. Cost-utility analysis of tiotropium versus usual care in patients with COPD in the UK and Belgium. Respir Med. 2012;106(12):1722-33. doi:10.1016/j.rmed.2012.09.006.

88. Diabetes Trial Unit. UKPDS Outcomes Model. University of Oxford. 2013. http://www.dtu.ox.ac.uk/outcomesmodel/. Accessed 10 June 2015.

89. Clarke P, Gray A, Legood R, Briggs A, Holman R. The impact of diabetes-related complications on healthcare costs: Results from the United Kingdom Prospective Diabetes Study (UKPDS Study No. 65). Diabet Med. 2003;20(6):442-50. doi:10.1046/j.14645491.2003.00972.x.

90. Pharmaceutical Services Negotiating Committee. NMS statistics. http://psnc.org.uk/funding-and-statistics/nhs-statistics/nms-statistics/. Accessed 21 Jan 2017 